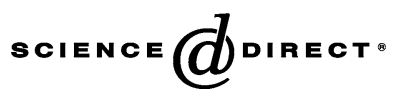

Life Sciences 77 (2005) 2514-2528
Life Sciences

www.elsevier.com/locate/lifescie

\title{
Effect of preventive and regressive isosorbide 5-mononitrate treatment on catecholamine levels in plasma, platelets, adrenals, left ventricle and aorta in cyclosporin A-induced hypertensive rats
}

\author{
Flávio Reis ${ }^{\text {a }}$ Luís Rocha ${ }^{\text {a }}$, Luísa Ponte ${ }^{\text {a }}$, Teresa Alcobia ${ }^{a}$, Luís Almeida ${ }^{a}$, \\ Carlos Costa-Almeida ${ }^{\mathrm{b}}$, Frederico Teixeira ${ }^{\mathrm{a}, *}$ \\ ${ }^{a}$ Therapeutics Unit, Institute of Pharmacology and Experimental Therapeutics, Medicine Faculty, Coimbra University, \\ 3004-504 Coimbra, Portugal \\ b Institute of Physiology, Medicine Faculty, Coimbra University, 3004-504 Coimbra, Portugal
}

Received 27 August 2004; accepted 19 January 2005

\begin{abstract}
Increased vascular reactivity associated with cyclosporin A (CsA)-induced arterial hypertension might result from increased vasoconstriction and/or decreased vasodilatation. The administration of organic NO donors could have beneficial effects by the NO-cGMP reposition, but there is the risk of sympathetic nervous system worsening by neuro-hormonal counter-regulation. We evaluate the effect of preventive and regressive (curative) isosorbide 5mononitrate (Is-5-Mn) treatment on blood pressures and on plasma, platelets, adrenals, left ventricle and aorta norepinephrine (NE) and epinephrine (E) contents, assessed by HPLC, in CsA-induced hypertensive rats. Five rat groups were tested: control (orange juice), CsA (5 mg/kg/day) and Is-5-Mn (150 mg/kg/day, bid) groups were treated for 7 weeks; preventive group (Is-5-Mn+CsA): Is-5-Mn during 2 weeks plus 7 weeks of Is-5-Mn + CsA; regressive group (CsA+Is-5-Mn): CsA during 7 weeks plus 5 weeks of CsA+Is-5-Mn. The increased BP in the CsA group was prevented, but was not reverted, by concomitant Is-5-Mn treatment. In the CsA-treated rats, there was a noticeable decrease in left ventricle NE and E contents and aorta NE levels and a moderate increase in circulating catecholamines, without significant effect in the adrenals values. When Is-5-Mn was preventively used, the CsA-induced effect on left ventricle and aorta was prevented. Concomitantly, however, the plasma-platelet catecholamine balance was disrupted, accumulating NE in plasma, whereas E increased in aorta, mimic the single Is-5-Mn-treated group. In opposition, in the group used as regressive Is-5-Mn therapy, the adrenals contents were higher compared with the CsA-group and, simultaneously, the CsA-evoked effects on circulating, left ventricle and
\end{abstract}

\footnotetext{
* Corresponding author. Tel.: +351 239 857777; fax: +351 239836200.

E-mail address: fredjt@ci.uc.pt (F. Teixeira).
} 
aorta catecholamines were not reverted. In conclusion, regressive Is-5-Mn therapy was unable to attenuate CsAinduced catecholamine changes and BP values even worsened. On the contrary, preventive Is-5-Mn treatment prevented the catecholamine changes on left ventricle and aorta, but increased plasma $\mathrm{NE}$ and aorta $\mathrm{E}$ accumulation. Even though with those effects, hypertension development was totally prevented, suggesting that peripheral SNS per se cannot fully explain CsA-induced hypertension. Furthermore, Is-5-Mn might produce beneficial effects only if preventively employed but, considering the changes on peripheral catecholamine contents, a judicious evaluation of the nitrate therapy impact is recommended in order to avoid further deleterious effects.

(C) 2005 Elsevier Inc. All rights reserved.

Keywords: Cyclosporin A; Arterial hypertension; Isosorbide 5-mononitrate; Nitric oxide; Catecholamines; Plasma; Platelets; Peripheral tissues

\section{Introduction}

Cyclosporin A (CsA) has greatly improved morbidity and mortality in transplanted patients during the last decades (Cortesini, 2004). However, albeit the high immunosuppressive efficacy, its clinical use is commonly associated with undesirable serious side effects, such as nephrotoxicity (Cattaneo et al., 2004) and arterial hypertension development (Textor et al., 2000). The prevalence rate for this posttransplant hypertension is elevated (between 65 and 100\%, according to Taler et al., 1999) and might endanger the transplant successful and long-term allograft survival (Mange et al., 2000).

Although widely investigated, the pathophysiological mechanisms underlying CsA-induced hypertension are not fully elucidated until now; but an increased vascular reactivity seems to be a consensual data (Cartier et al., 1994). The activation of sympathetic neural pathways leading to adrenergically mediated vasoconstriction has been proposed. Almost all the animal studies have been suggesting a CsA-induced sympathetic overactivation, by means of increased pre-synaptic neurotransmitter release, augmented vascular contraction in response to nerve stimulation, altered catecholamine contents or enhanced neurotransmission (Xue et al., 1987; Duruibe et al., 1990; Lyson et al., 1994; Zhang and Victor, 2000). Our previous studies, through the evaluation of peripheral catecholamine contents in rats under CsA treatment with therapeutic-related doses, have also suggested a relevant sympathetic dysfunction (Reis et al., 2000; Tavares et al., 2003). However, in human transplant recipients, the results were miscellaneous. While some studies have suggested an increased neural traffic related with CsA administration (Scherrer et al., 1990; Seals et al., 1993; Sander et al., 1996; Lucini et al., 2000; van de Borne et al., 2001), others have indicated normal or decreased sympathetic activity or no determinant influence for the CsA-hypertension (Floras et al., 1991; Elam et al., 1993; Kaye et al., 1993; Stein et al., 1995; Carvalho et al., 1999; Bouhaddi et al., 2004). The time elapsed after transplantation might possibly explain some of the discrepant results (van de Borne et al., 2001). However, the use of adrenergic modulators as primary treatment for CsA-induced hypertension remains debatable.

Decreased vasodilatation, as well as increased vasoconstriction, might play a central role in the exacerbated vascular reactivity. Actually, CsA-associated endothelial damage and decreased endothelium-dependent and independent relaxation were also previously demonstrated (Zoja et al., 1986; Stephan et al., 1995; El-Mas et al., 2004). Nitric oxide (NO) participates in the blood pressure control 
(Das and Kumar, 1995) and a pivotal role for a NO-cGMP (cyclic guanosine-3', $5^{\prime}$-monophosphate) pathway impairment has been gaining substantial attention during the last years (Marumo et al., 1995; Oriji and Keiser, 1998). However, despite widely studied, its contribution for the CsA-induced vascular dysfunction and hypertension, as well as the possible benefits of L-arginine supplementation (the most tested therapeutic intervention), remains incompletely elucidated (O'Neil et al., 1991; Stroes et al., 1997; Lassila et al., 2001; Santiago et al., 2003; El-Mas et al., 2004). In previous studies from our group, while L-arginine administration has shown inefficacy in preventing CsA-induced hypertension (Reis et al., 2002), the preliminary results with a different NO donor drug, the organic nitrate isosorbide 5mononitrate (Is-5-Mn), have demonstrated promising results (Reis et al., 2003).

Despite those beneficial effects, long-term nitrate dietary supplementation might interfere with the sympathetic activity, namely as a result of compensatory counter-regulation (Megson, 2000). Thus, this work intended to study the effect of preventive and regressive (curative) Is-5-Mn treatment on blood pressures and on plasma, platelets, adrenals, left ventricle and aorta norepinephrine (NE) and epinephrine (E) contents in CsA-induced hypertensive rats.

\section{Material and methods}

\section{Animals and diets}

Male Wistar rats (Charles River Laboratories Inc., Barcelona, Spain), 280-300 g, were maintained in an air conditioned room $\left(22-24{ }^{\circ} \mathrm{C}\right)$ with humidity of $60 \%$, subjected to 12 -h dark-light cycles and given standard laboratory rat chow (IPM-R20, Letica, Barcelona, Spain) and water ad libitum. Animal experiments were conducted according to the European Convention on Animal Care, and the Portuguese Foundation for Science and Technology approved the research project containing the study. After a period of adaptation of at least 1 week, the rats were divided into 5 groups (each with 8 rats) treated with the following oral diets: control group-receiving only orange juice during 7 weeks; CsA group-receiving $5 \mathrm{mg} / \mathrm{kg}$ body weight $(\mathrm{BW}) /$ day of $\mathrm{CsA}$ (Sandimmune Neoral ${ }^{\circledR}$, Novartis Farma), dissolved in orange juice, for the period of 7 weeks; Is-5-Mn group-receiving 150 $\mathrm{mg} / \mathrm{kg} \mathrm{BW}$ /day (bid) of Is-5-Mn (Monopront ${ }^{\circledR}$, Ferraz-Lynce SA) during 7 weeks; preventive group (Is-5-Mn+CsA)-receiving $150 \mathrm{mg} / \mathrm{kg} \mathrm{BW/day} \mathrm{(bid)} \mathrm{of} \mathrm{Is-5-Mn} \mathrm{for} 2$ weeks and the same dose of Is$5-\mathrm{Mn}$ plus CsA (5 mg/kg BW/day) during an additional period of 7 weeks; regressive group (CsA + Is-5-Mn)-receiving $5 \mathrm{mg} / \mathrm{kg} \mathrm{BW/day} \mathrm{of} \mathrm{CsA} \mathrm{during} 7$ weeks and the same dose of CsA plus $150 \mathrm{mg} / \mathrm{kg} \mathrm{BW} /$ day (bid) of Is-5-Mn for the additional period of 5 weeks. All the administrations were performed using an appropriate esophagi canola, between $1700 \mathrm{~h}$ and $1800 \mathrm{~h}$ for control and CsA-treated rats. In order to have a daily nitrate-low/free period of about $4-5 \mathrm{~h}$ to overcome hypothetic organic nitrate tolerance, Is-5-Mn bid administration was made asymmetrically at 1000 $\mathrm{h}$ and at $1700 \mathrm{~h}$. All the determinations were carried out in all the rat groups at the end of the corresponding treatments: week 7 for the control, CsA and Is-5-Mn groups, week 9 for the Is-5$\mathrm{Mn}+\mathrm{CsA}$ group and week 12 for CsA+Is-5-Mn group. The CsA dose of $5 \mathrm{mg} / \mathrm{kg} / \mathrm{day}$ was chosen because the rat blood concentrations achieved are well-correlated with the human "maintenance" dose used in clinical practice of transplantation (Tavares et al., 2002). Is-5-Mn dose was selected by means of preliminary studies concerning its efficacy in preventing CsA-induced hypertension development (Reis et al., 2003). 


\section{Blood pressures and heart rate assessment}

Systolic blood pressure (SBP), diastolic blood pressure (DBP) and mean blood pressure (MBP) and heart rate (HR) values were obtained using a tail-cuff sphygmomanometer LE 5001 (Letica, Barcelona, Spain) in appropriate contention cages. Before the measurements, the rats were warmed for 10-20 min at $25-30{ }^{\circ} \mathrm{C}$ in order to allow the detection of tail artery pulsations and to achieve the pulse level ready. BP and $\mathrm{HR}$ values were obtained by averaging 8-10 measurements. To minimize stress-induced fluctuations in BP, all the rats were adapted to appropriate cages and to measurements during at least 2 weeks before the beginning of administrations. The same person took the final values in the same peaceful environment between $1400 \mathrm{~h}$ and $1800 \mathrm{~h}$. Blood pressure and HR were assessed in all the rat groups under study, at several different periods of treatment: a group of 30 rats was random chosen between the rats of all the groups before the beginning of treatments, in order to be used as the time 0 value; the control and the CsA group were assessed at the end of the treatments (week 7); the Is-5-Mn+CsA group was evaluated before the concomitant CsA administration (Is-5-Mn group-week 2) and at the end of the treatment (week 9); the CsA+ Is-5-Mn group was measured before simultaneous Is-5-Mn administration (CsA group-week 7) and at the end of the treatment (week 12).

\section{Body and tissues (cardiac and adrenal) weights and hypertrophy indexes}

At the end of each treatment, the body weight (BW), the whole heart weight (HW), the left ventricle weight (LVW) and the adrenals (2: left plus right) weight (AW) were measured in all the rats under study. The cardiac hypertrophy indexes were indicated by the heart weight in grams per kilogram body weight (HW/BW) and by the left ventricle weight in grams per kilogram body weight (LVW/BW). The adrenals hypertrophy index was expressed by the adrenals weight (2: left and right) in grams per kilogram body weight (AW/BW).

\section{Catecholamine assay}

$\mathrm{NE}$ and $\mathrm{E}$ levels in plasma, platelets, adrenals, left ventricular tissue and aorta tissue were evaluated by HPLC, using 3,4-dihydroxybenzylamine (DHBA) as internal standard.

\section{Plasma and platelet sample preparation}

The platelet pellet and the plasma samples from all the rat groups were obtained as previous described (Reis et al., 2000) and added reduced glutathione $(0.250 \mathrm{M})$ to prevent amine degradation. In brief, $2 \mathrm{ml}$ of each of these fractions, $100 \mathrm{ng} / \mathrm{ml}$ of DHBA, $50 \mathrm{mg}$ of alumina and $1 \mathrm{ml}$ of Tris- $\mathrm{HCl}$ buffer $(1.5 \mathrm{M}$, $\mathrm{pH}$ 8.6) containing $0.1 \mathrm{M} \mathrm{Na}_{2}$-EDTA were added. The mixture was then shaken for $10 \mathrm{~min}$, allowed to stand for a few minutes to sediment alumina, and the supernatant was aspirated. The alumina was then washed three times with ultra-pure water and transferred to an appropriate microfilter system, where adsorbed catecholamines were finally obtained by centrifugation $(1000 \times g$ for $1 \mathrm{~min})$ after having added perchloric acid $(0.1 \mathrm{M})$.

\section{Aorta, adrenals and left ventricle sample preparation}

At the end of each treatment, the rats were sacrificed by cervical dislocation and the aorta, the adrenal glands and the heart were immediately removed, placed in ice-cold Krebs' buffer, carefully cleaned of 
adherent fat and connective tissue and then weighted. The adrenals (2: left plus right), the left ventricular tissue and a small segment of the abdominal aorta were then homogenized in perchloric acid $(0.1 \mathrm{M}$, Sigma) at $4{ }^{\circ} \mathrm{C}$ and then centrifuged at $2500 \times \mathrm{g}$ for $15 \mathrm{~min}$ at $4{ }^{\circ} \mathrm{C}$. The supernatant was filtered by microcentrifuge filter (Spin-X HPLC, Costar ${ }^{\circledR}$, Corning Inc. NY, USA) and the filtrate was used for the catecholamine assay, performed according to above described conditions.

\section{Chromatographic conditions}

The HPLC system consisted of a Gilson Applied Chromatographic System with a Biophase ODS RP18 analytical column $(250 \times 4.6, \varnothing=5 \mu$; Bioanalytical Systems Inc., U.S.A.). Separation and detection was achieved using the conditions previously described (Reis et al., 2000) in an isocratic solvent system of acetate-citrate buffer (sodium acetate $0.1 \mathrm{M}$, citric acid $0.1 \mathrm{M}$ ), containing sodium 1octanesulfonate $(0.5 \mathrm{mM})$, EDTA $(0.15 \mathrm{mM})$, dibutylamin $(1 \mathrm{mM})$ and $10 \%$ methanol.

\section{Catecholamine levels quantification}

$\mathrm{NE}$ and $\mathrm{E}$ contents were measured by using known concentrations of the corresponding standards (Sigma Chemical Co.) and the internal standard DHBA, and were quantified by means of the peak area ratio. Chromatograms were obtained using the appropriate software (Gilson 712 HPLC Controller version 1.30, Gilson Medical Electronics Inc., Villiers-Le-Bel, France). Concentrations were expressed in: $\mathrm{ng} / \mathrm{ml}$ for plasma, $\mathrm{pg} / 10^{9}$ plat. for the platelets, $\mu \mathrm{g} / \mathrm{g}$ wet tissue for the adrenals and $\mathrm{ng} / \mathrm{g}$ wet tissue for left ventricle and aorta.

Drugs

Cyclosporin A (Sandimmune Neoral ${ }^{\circledR}$ ) was given by Novartis Pharma, Lisbon, Portugal; isosorbide 5-mononitrate (Monopront ${ }^{\circledR}$ ) was supplied by Ferraz, Lynce SA (Lisbon, Portugal). Alumina was purchased from Bioanalytical Systems Inc. (West Lafayette, ID, U.S.A.). The solvents of high purity for the chromatographic quantifications were obtained from Merk (Darsmstadt, Germany). The internal standard DHBA and the catecholamine standards, as well as all the other chemicals were purchased from Sigma Chemical Co. (St. Louis, MO, U.S.A).

\section{Statistical analysis}

Results were expressed as means \pm standard error of the mean (SEM). Groups were tested for differences by performing ANOVA followed by Fisher's Protected-Least-Significant-Difference (PLSD) post-hoc test, using the Statview 4.53 software from Abacus Concepts Inc. (Berkeley, CA, USA). Differences were considered statistically significant at a value $P<0.05(* P<0.05 ; * * P<0.01$ and *** $P<0.01$ : vs. the control group; ${ }^{\dagger} P<0.05 ;{ }^{\dagger \dagger} P<0.01$ and ${ }^{\dagger \dagger} P<0.001$ vs. the CsA-treated group).

\section{Results}

Blood pressures and heart rate

After 7 weeks of CsA treatment, there was a significant SBP, DBP and MBP increase $(P<0.001$ for each) when compared with the control (Table 1). In opposition, in the Is-5-Mn+CsA rats, no significant 
Table 1

Systolic, diastolic and mean blood pressure and heart rate in the control, CsA, Is-5-Mn+CsA, CsA+Is-5-Mn and Is-5-Mn groups throughout the treatments

\begin{tabular}{|c|c|c|c|c|c|}
\hline Group & $n$ & SBP (mm Hg) & DBP (mm Hg) & MBP (mm Hg) & HR (beats/minutes) \\
\hline Before treatments & 30 & & & & \\
\hline Random group & & $111.6 \pm 0.7$ & $94.6 \pm 1.0$ & $100.1 \pm 0.7$ & $341.3 \pm 3.0$ \\
\hline After treatments & 8 & & & & \\
\hline Control & & $114.9 \pm 3.1$ & $99.1 \pm 1.8$ & $104.3 \pm 1.9$ & $339.1 \pm 6.3$ \\
\hline $\mathrm{CsA}$ & & $146.2 \pm 4.5^{* * *}$ & $124.9 \pm 4.5^{* * *}$ & $136.6 \pm 5.8^{* * *}$ & $375.5 \pm 6.9^{* *}$ \\
\hline Is-5-Mn+ CsA & & $114.3 \pm 1.9 \ddagger \dagger \dagger$ & $97.0 \pm 3.3 \ddagger \dagger \ddagger$ & $100.4 \pm 4.0 \ddagger \dagger \ddagger$ & $368.4 \pm 11.9$ \\
\hline CsA + Is-5-Mn & & $159.7 \pm 5.5 \ddagger$ & $132.8 \pm 2.8$ & $140.2 \pm 3.0$ & $389.2 \pm 10.8$ \\
\hline Is-5-Mn & & $116.8 \pm 2.4$ & $104.1 \pm 2.6$ & $108.5 \pm 2.6$ & $360.0 \pm 6.8^{*}$ \\
\hline
\end{tabular}

CsA: cyclosporin A; Is-5-Mn: isosorbide 5-mononitrate; SBP: systolic blood pressure; DBP: diastolic blood pressure; MBP: mean blood pressure; HR: heart rate. Values are means \pm S.E.M. of $n$ (indicated) rats. Significant differences between the groups are expressed: $* * P<0.01$ and $* * * P<0.001$ vs. the control group; $\ddagger P<0.05$ and $\ddagger \dagger \ddagger P<0.001$ vs. the CsA group.

differences were obtained when compared with the control (after 2 weeks of single Is-5-Mn treatment or at the end of Is-5-Mn+CsA administration). However, statistically significant lower values were demonstrated when compared with the CsA group (Table 1). That is, the CsA-induced BP rise was prevented. Contrarily, in the group firstly treated only with CsA during 7 weeks and then with both drugs for an additional period of 5 weeks (CsA + Is-5-Mn group), the systolic $(P<0.05)$, the diastolic and the mean BP have revealed even higher values than those of the CsA group, demonstrating no CsA-induced hypertension reversion. Quite the opposite, even a worsening of the effect was observed (Table 1).

Heart rate values were also significantly higher in the CsA-treated rats $(P<0.01)$ when compared with those of the control group. The single Is-5-Mn group also has demonstrated a higher HR value $(P<0.05)$ in comparison with the control group. In the preventive and regressive Is-5-Mn groups (Is-5-Mn $+\mathrm{CsA}$ and CsA + Is-5-Mn, respectively), the CsA-induced HR increment was not prevented or reverted, being the values identical to those of the CsA group (Table 1).

\section{Cardiac and adrenal glands weights and hypertrophy indexes}

The body, whole heart, left ventricle and adrenals weights were evaluated at the end of treatments: week 7 for the control, CsA and Is-5-Mn groups; week 9 for the Is-5-Mn+CsA group and week 12 for the CsA+Is-5-Mn group. The cardiac weights (HW and LVW) and hypertrophy indexes (HW/BW and LVW/BW) were identical in all the groups under study (Table 2). Concurrently, no statistically significant differences were encountered in adrenals weight (2: left plus right) and hypertrophy index $(\mathrm{AW} / \mathrm{BW})$ between the 5 groups (Table 2).

\section{Plasma and platelet catecholamine levels}

After 7 weeks of treatment in the CsA-treated rats, the plasma NE $(1.66 \pm 0.15 \mathrm{ng} / \mathrm{ml})$ and $\mathrm{E}$ $(0.49 \pm 0.04 \mathrm{ng} / \mathrm{ml})$ levels were numerically higher than those of the control rats $(\mathrm{NE}: 1.33 \pm 0.20 \mathrm{ng} / \mathrm{ml}$; E: $0.37 \pm 0.04 \mathrm{ng} / \mathrm{ml}$ ), but without reaching statistically significance. Similar values were also obtained in the Is-5-Mn group (Fig. $1 \mathrm{~A}_{1}$ and $\mathrm{A}_{2}$ ). The groups treated concomitantly with CsA and Is-5-Mn demonstrated different patterns. Actually, in the preventive group (Is-5-Mn+CsA), there were 
Table 2

Weights of the body, whole heart, left ventricle and adrenals and cardiac and adrenal hypertrophy indexes in the control, CsA, Is-5-Mn+ CsA, CsA + Is-5-Mn and Is-5-Mn groups at the end of the corresponding treatments

\begin{tabular}{llllllll}
\hline Group & BW $(\mathrm{kg})$ & $\mathrm{HW}(\mathrm{g})$ & LVW $(\mathrm{g})$ & $\mathrm{HW} / \mathrm{BW}(\mathrm{g} / \mathrm{kg})$ & $\mathrm{LVW} / \mathrm{BW}(\mathrm{g} / \mathrm{kg})$ & $\mathrm{AW}(\mathrm{g})$ & $\mathrm{AW} / \mathrm{BW}(\mathrm{g} / \mathrm{kg})$ \\
\hline Control & $0.38 \pm 0.01$ & $1.17 \pm 0.05$ & $0.88 \pm 0.05$ & $3.11 \pm 0.11$ & $2.34 \pm 0.11$ & $0.092 \pm 0.013$ & $0.24 \pm 0.30$ \\
CsA & $0.42 \pm 0.01$ & $1.23 \pm 0.09$ & $0.93 \pm 0.06$ & $2.93 \pm 0.23$ & $2.29 \pm 0.21$ & $0.090 \pm 0.006$ & $0.21 \pm 0.16$ \\
Is-5-Mn+CsA & $0.38 \pm 0.01$ & $1.21 \pm 0.03$ & $0.86 \pm 0.03$ & $3.18 \pm 0.08$ & $2.29 \pm 0.08$ & $0.094 \pm 0.005$ & $0.24 \pm 0.12$ \\
CsA+Is-5-Mn & $0.42 \pm 0.01$ & $1.21 \pm 0.06$ & $0.94 \pm 0.08$ & $2.85 \pm 0.07$ & $2.21 \pm 0.18$ & $0.078 \pm 0.006$ & $0.18 \pm 0.15$ \\
Is-5-Mn & $0.39 \pm 0.03$ & $1.11 \pm 0.04$ & $0.85 \pm 0.03$ & $2.87 \pm 0.12$ & $2.21 \pm 0.21$ & $0.085 \pm 0.029$ & $0.22 \pm 0.07$ \\
\hline
\end{tabular}

CsA: cyclosporin A; Is-5-Mn: isosorbide 5-mononitrate; BW: body weight; HW: whole heart weight; LVW: left ventricle weight; AW: adrenals (2) weight; $\mathrm{HW} / \mathrm{BW}(\mathrm{g} / \mathrm{kg})$ : heart weight in grams per kilogram body weight; LVW/BW (g/kg): left ventricle weight in grams per kilogram body weight; AW/BW $(\mathrm{g} / \mathrm{kg})$ : adrenals weight (2: left and right) in grams per kilogram body weight. Values are means \pm S.E.M. of 8 rats for each group.

significantly increased NE levels $(2.28 \pm 0.45 \mathrm{ng} / \mathrm{ml} ; P<0.05)$ and tendentious (not significant) higher $\mathrm{E}$ contents, indicating an effect even more pronounced than the effect observed in the CsA group. In opposition, in the group used as regressive therapy (CsA + Is-5-Mn), no significant differences in NE and E contents were obtained when compared with the CsA-treated rats (Fig. $1 \mathrm{~A}_{1}$ and $\mathrm{A}_{2}$ ).

\section{(A) Plasma norepinephrine}

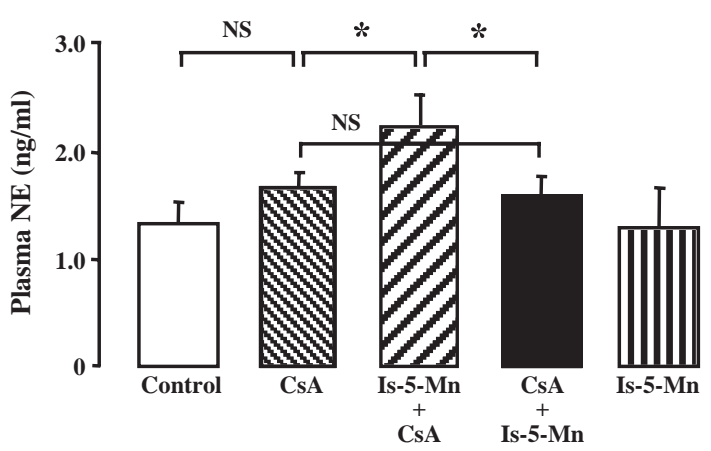

$\left(\mathbf{A}_{2}\right)$ Plasma epinephrine

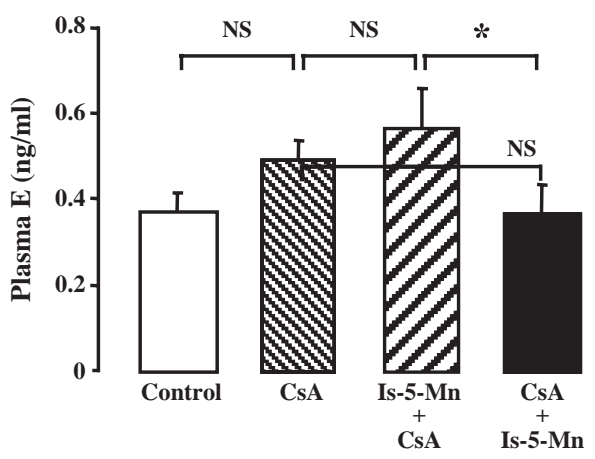

$\left(B_{1}\right)$ Platelet norepinephrine

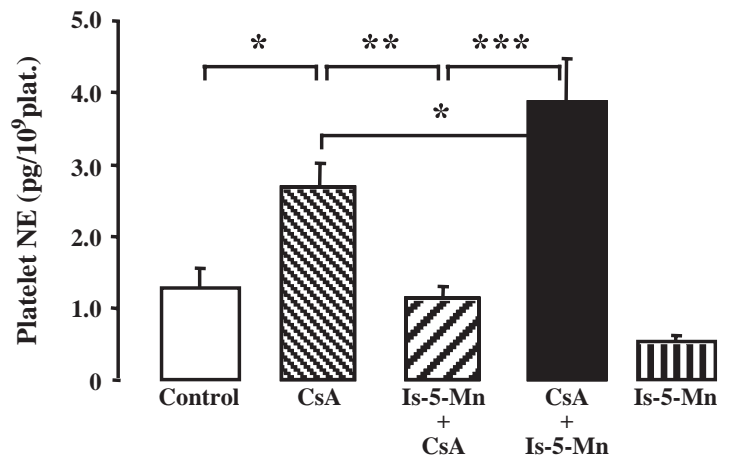

$\left(B_{2}\right)$ Platelet epinephrine

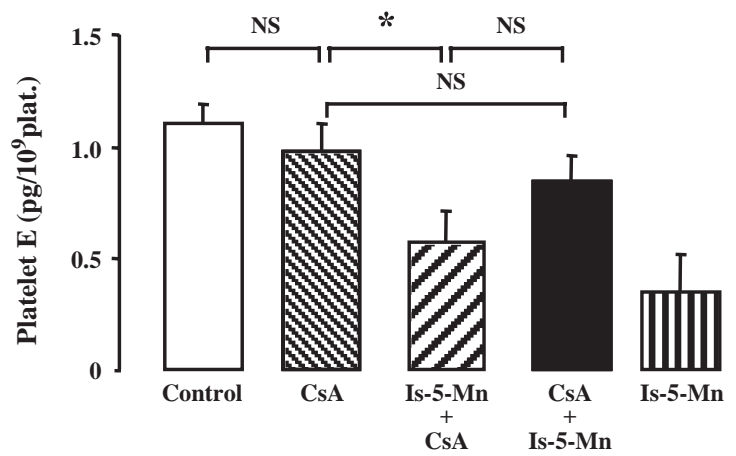

Fig. 1. Plasma (A) and platelet (B) norepinephrine ( $\left.{ }_{1}\right)$ and epinephrine $\left({ }_{2}\right)$ concentrations in the control, CsA, Is-5-Mn + CsA, $\mathrm{CsA}+\mathrm{Is}-5-\mathrm{Mn}$ and Is-5-Mn groups. Values are means \pm S.E.M. of 8 rats for each group. Significant differences between the groups are expressed: $* P<0.05 ; * * P<0.01 ; * * * P<0.001$; NS: Non-significant. 
The platelet catecholamines concentrations have revealed a higher NE value $\left(2.69 \pm 0.32 \mathrm{pg} / 10^{9} \mathrm{plat}\right.$; $P<0.05)$ in the CsA group than in the control, without significant differences on E levels (Fig. $1 \mathrm{~B}_{1}$ and $\mathrm{B}_{2}$ ). In the Is-5-Mn treated rats, there were significant lower values of $\mathrm{NE}$ and $\mathrm{E}$ in comparison with the control. Moreover, similar concentrations were also found in the Is-5-Mn+CsA group, being the values of NE and E statistically significant $(P<0.01$ and $P<0.05)$ when compared with those of the CsA group. These data indicate that when the rats were previously treated with Is-5-Mn before the concomitant administration with CsA, the effect of the single Is-5-Mn treatment was maintained. On the other hand, in the CsA+Is-5-Mn group, the results were identical to those obtained in the single CsA-treated group, being platelet $\mathrm{NE}$ level even higher than in the CsA group and E concentration also unchanged (Fig. $1 \mathrm{~B}_{1}$ and $\mathrm{B}_{2}$ ). While the preventive Is-5-Mn treatment seems to essentially preserve the effects observed in the group treated solely with Is-5-Mn, the regressive Is-5-Mn treatment seems to only slightly affect the CsA effects already established, demonstrating no regressive corrections.

\section{Peripheral tissues (adrenals, left ventricle and aorta) catecholamines levels}

The NE and E contents in the adrenals of the CsA-treated rats were identical to those of the control group. In the group first treated with Is-5-Mn during 2 weeks and further simultaneously administrated

\section{( $\left.A_{1}\right)$ Adrenals norepinephrine}

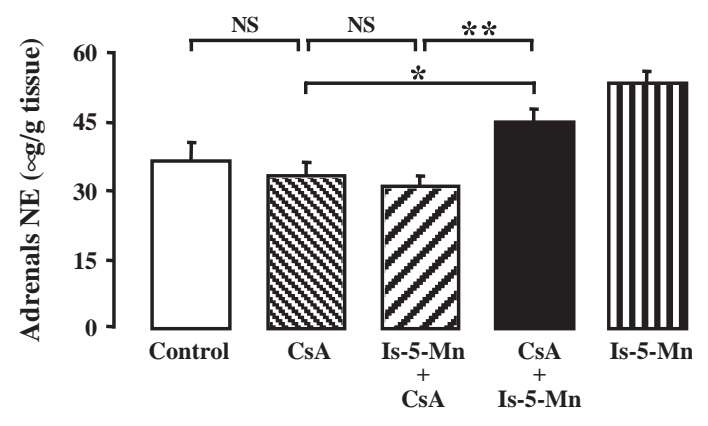

$\left(A_{2}\right)$ Adrenals epinephrine

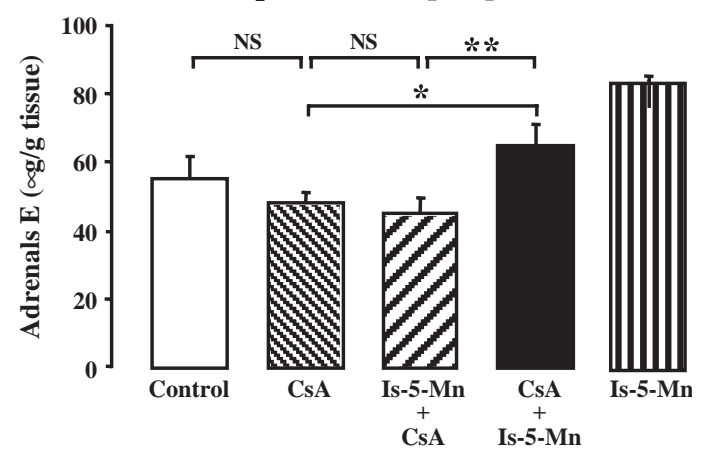

Fig. 2. Adrenals norepinephrine $\left(\mathrm{A}_{1}\right)$ and epinephrine $\left(\mathrm{A}_{2}\right)$ contents in the control, CsA, Is-5-Mn+CsA, CsA+Is-5-Mn and Is5 -Mn groups. Values are means \pm S.E.M. of 8 rats for each group. Significant differences between the groups are expressed: $* P<0.05 ; * * P<0.01 ; \mathrm{NS}$ : Non-significant. 
with CsA for 7 weeks (Is-5-Mn+CsA), the concentrations were also similar to those observed in the CsA and in the control rats (Fig. 2). However, both in the group treated singly with Is-5-Mn and in the group treated initially with $\mathrm{CsA}$ and then with $\mathrm{CsA}$ and Is-5-Mn (CsA+Is-5-Mn), there were significantly higher NE and $\mathrm{E}$ contents $(P<0.05$ for both catecholamines) when compared with the CsA group (Fig. 2).

The left ventricular tissue NE content was lower $(P<0.05)$ in the CsA-treated group than in the control (Fig. 3A 1 ). Concurrently, E concentration was highly inferior in the CsA group than in the control $(P<0.001)$ (Fig. 3 $\left.\mathrm{A}_{2}\right)$. In the Is-5-Mn group, the $\mathrm{NE}$ and $\mathrm{E}$ levels were identical to those of the control group, which seems to indicate no particular effect of Is-5-Mn on the left ventricular mechanisms of $\mathrm{NE}$ and $\mathrm{E}$ accumulation and release. The groups treated concomitantly with CsA and Is-5-Mn demonstrated different patterns. Therefore, in the group preventively tested (Is-5-Mn+CsA), the CsAinduced left ventricular NE $(P<0.05)$ and $\mathrm{E}(P<0.001)$ changes were totally prevented, being the numerical values identical to those of the control group. On the contrary, in the group used as regressive therapy (CsA + Is-5-Mn), no significant differences in NE and E contents were obtained when compared with the CsA-treated rats (Fig. $3 \mathrm{~A}_{1}$ and $\mathrm{A}_{2}$ ), which suggests the inexistence of regressive effect of Is-5$\mathrm{Mn}$ when the CsA-induced changes were already present.

$\left(A_{1}\right)$ Left ventricle norepinephrine

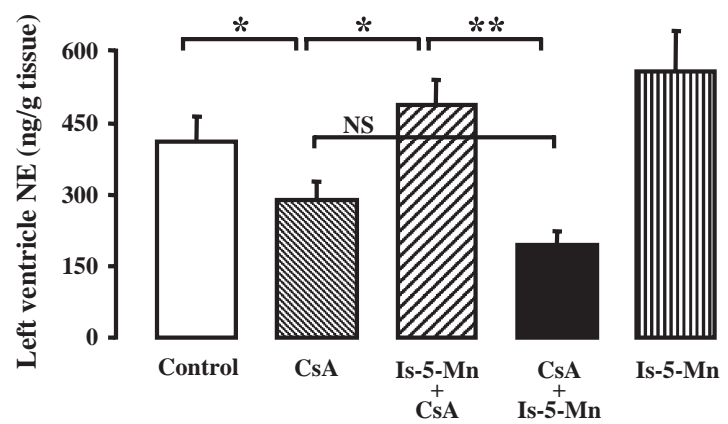

$\left(A_{2}\right)$ Left ventricle epinephrine

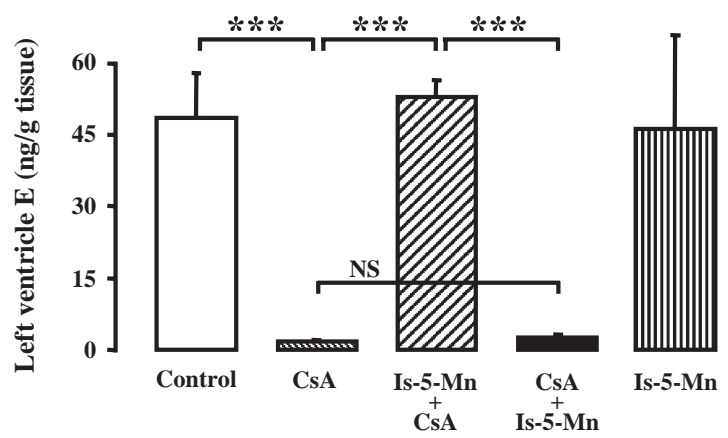

$\left(B_{1}\right)$ Aorta norepinephrine

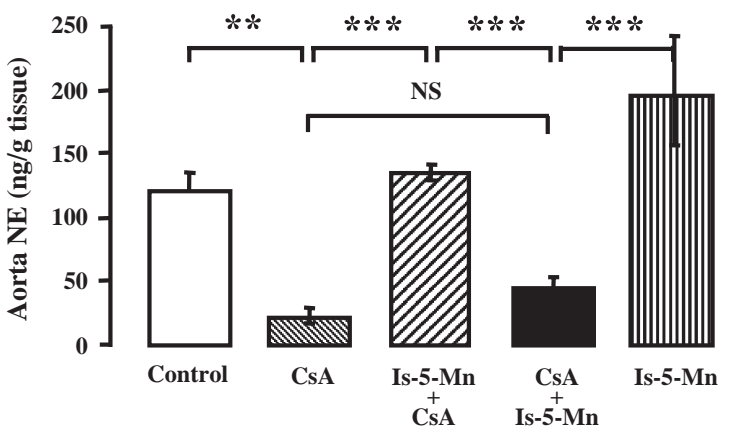

$\left(B_{2}\right)$ Aorta epinephrine

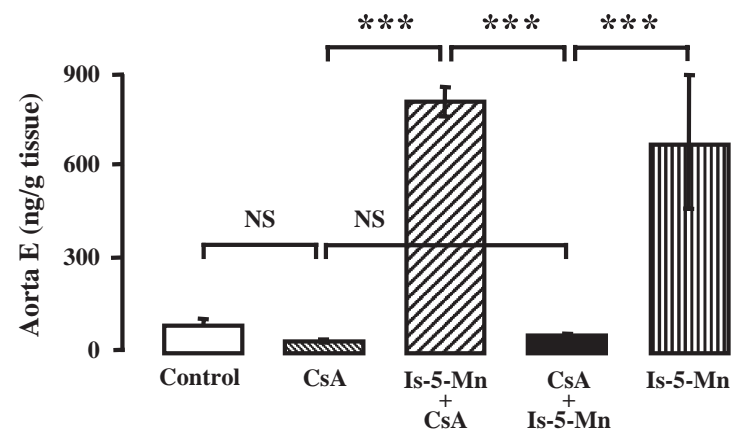

Fig. 3. Left ventricle (A) and aorta (B) norepinephrine (1) and epinephrine ( $\left.{ }_{2}\right)$ contents in the control, CsA, Is-5-Mn+CsA, $\mathrm{CsA}+\mathrm{Is}-5-\mathrm{Mn}$ and Is-5-Mn groups. Values are means \pm S.E.M. of 8 rats for each group. Significant differences between the groups are expressed: ${ }^{*} P<0.05 ; * * P<0.01 ; * * * P<0.001$; NS: Non-significant. 
The aorta NE content was significantly lower in the CsA group than in the control $(P<0.01)$, but the E concentration found was identical in both groups (Fig. $3 \mathrm{~B}_{1}$ and $\left.\mathrm{B}_{2}\right)$. The preventive Is-5-Mn treatment has prevented the CsA-induced NE content decrease $(P<0.001)$ and, simultaneously, has increased the E accumulation. The value obtained was highly significant $(P<0.001)$ when compared with the CsA group, in which a normal aorta $\mathrm{E}$ accumulation was demonstrated. The Is-5-Mn+CsA group effect resembles the pattern observed in the group treated solely with Is-5-Mn, where normal NE and higher E concentration in aorta was found (Fig. $3 \mathrm{~B}_{1}$ and $\mathrm{B}_{2}$ ). In the $\mathrm{CsA}+\mathrm{Is}-5-\mathrm{Mn}$ group, identical NE and $\mathrm{E}$ aorta contents were obtained compared to those of the CsA-treated rats, demonstrating no ability to revert the CsA-induced effects.

\section{Discussion}

In this study, the therapeutic application of Is-5-Mn to prevent/attenuate CsA-evoked BP rise originated divergent effects: when used preventively (Is-5-Mn+CsA group), the hypertension was prevented and when employed as regressive/curative therapy (CsA + Is-5-Mn group), the BP rise was even higher. This discovery opens good perspectives for the organic nitrates, in particular for Is-5-Mn, as therapy for CsA-induced arterial hypertension development if preventively used. Furthermore, the effect was demonstrated even after a large period ( 7 weeks) of concomitant treatment with CsA, indicating that if administered bi-daily in asymmetrical doses before the CsA treatment, as was done in our study, it does not originate relevant tolerance and lost of effect given that the preventive effect on BP rise was maintained. When the CsA effects were already established, the same lack of tolerance by concomitant Is-5-Mn treatment could not be ensured since it was inefficient in attenuating/reverting hypertension development.

Previous studies from our group, using this rat model treated with CsA doses related with those used in clinical therapeutic practice to prevent allograft rejection, have suggested a sympathetic nerve system overactivation (Reis et al., 2000; Tavares et al., 2003). As recognized, long-term nitrate dietary supplementation might interfere with SNS activity. Thus, notwithstanding the promising previous results concerning the prevention of CsA-induced BP rise (Reis et al., 2003), the hypothetic impact of this preventive and regressive/curative Is-5-Mn treatment on peripheral SNS activity should imperatively be evaluated. Norepinephrine, the main neurotransmitter from the sympathetic nerves, and epinephrine, which functions as a circulating hormone almost entirely derived from the adrenal medulla, are released to the circulation upon sympathetic stimulation and then taken by peripheral tissues, such as the heart and aorta. The platelets, usually seen as peripheral models of the monoaminergic neurons (Stahl, 1985), selectively uptake catecholamines from the plasma and store them for relatively long periods, thus overcoming possible regional differences, which is the main problem of plasma catecholamines analysis. Since platelets are not capable of synthesizing the monoamines, their content derives entirely from those released into the bloodstream by the adrenals or the SNS terminals and can be considered a reliable and stable long-term index of SNS activity (Chanberlain et al., 1990). Accordingly, the NE and E contents in plasma and platelets, as the main indicators of circulating levels, as well in adrenals, heart and aorta, the key relevant peripheral tissues involved in their synthesis and turnover, might be useful markers of the peripheral SNS activity in CsA-induced hypertension.

In which the peripheral tissues weights and hypertrophy indexes concerns, there were no significant differences between any of the groups under study, thus excluding these factors as important 
contributions for the catecholamines contents impairment. The CsA treatment produced minor differences on circulating NE and E levels when compared with the control group. The most relevant effect was an increased platelet NE concentration. Concomitantly, no significant effect was obtained in adrenals NE and E accumulation. However, left ventricle NE and E and aorta NE contents were lower than those of the control group. Peripheral tissues, such as the cardiac, take E from the plasma, which is released from the adrenal medulla upon sympathetic stimulation. The effect obtained might have resulted from decreased $\mathrm{E}$ soaked by the cardiac tissue from plasma and/or from increased release. However, since the adrenals and plasma E contents were found normal in the CsA group if compared with the control, there should have simultaneously occurred increased E degradation, which could be due to increased metabolism and/or conjugation. The NE content in peripheral tissues, such as heart and the aorta, is governed by the rates of NE release and turnover (which are determined by sympathetic stimulation and by uptake) and by the synthesis rate (which is mainly dependent of tyrosine hydroxylation). The decreased ventricle and aorta NE content in the CsA-treated rats might have resulted from an effect on one or more of the above mechanisms. As previously suggested by other authors, CsA might increase sympathetic discharge (Xue et al., 1987), which could be not compensated by enough synthesis. Moreover, in a previous study from our group, it was demonstrated that CsA decreases NE uptake, probably through a tyramine-like effect on membrane catecholamine transporter (Tavares et al., 2003). Those findings together support the idea of a combined effect of CsA, both exacerbating NE release and attenuating its uptake, but a defect on catecholamine synthesis by peripheral sympathetic nerves should also be considered. The decreased ventricle and aorta NE content is in accordance with the increased circulating concentration, which was particularly significant in the platelets.

The effects of simultaneous Is-5-Mn and CsA administration were dependent on the kind of treatment: preventive or regressive therapy. When the CsA action was already established, the Is-5-Mn treatment had no regressive impact on the decreased ventricle NE and E and aorta NE contents. Concurrently, adrenals NE and E levels were increased, as occurred in the group treated solely with the nitrate, and NE platelet concentration was even higher than in the CsA group. Thus, the changes in plasma and peripheral tissues catecholamine levels induced by previous CsA treatment were not reverted by subsequent Is-5-Mn administration, which suggests inefficacy of the organic nitrate in this kind of treatment. On the contrary, when administered before the concomitant treatment with CsA, Is-5-Mn was able to prevent the CsA-evoked diminishment of left ventricle NE and $\mathrm{E}$ and aorta NE contents. Furthermore, adrenals contents, which were normal in the CsA group, were unaffected. However, there was a noticeable platelet NE and E reduction compared with the CsA group, indicating that Is-5-Mn affects platelet catecholamines turnover: uptake, storage, metabolism/conjugation and or release. This singular effect on platelets, which was also patent in the group treated exclusively with Is-5-Mn, should be further investigated. Platelet NE and E content decrease was accompanied by an increased plasma NE concentration and by an augmented aorta E content. Although suggestive, a direct connection between these changes and the former platelet catecholamine alterations cannot be here addressed.

Interestingly, while the results observed in the group used as regressive therapy (CsA+Is-5-Mn) have mimic those observed in the CsA group, demonstrating no reversion capacity, the data obtained in the group used as preventive therapy (Is-5-Mn+CsA) have mimic, in almost all the parameters, those seem in the group under single Is-5-Mn administration. This finding indicates that Is-5-Mn treatment determines the catecholamine content variations when used previously (even in those parameters significantly influenced by the single CsA administration). If the lack of a regressive influence, in contrast with the beneficial preventive one, is a nitrate tolerance signal cannot be excluded. 
We have previously reported that CsA administration is associated with a decrease of NO-cGMP contents (Santiago et al., 2003), that might be corrected by previous Is-5-Mn treatment (Reis et al., 2003). From the present data, it is reliable to consider that the CsA influence on left ventricle NE and E and aorta NE contents might have a NO deficiency dependency. Studies from other groups have previously indicated that both the catecholamine release by some blood vessels and by the rat heart sympathetic nerves might be inhibited by NO (Cohen and Weisbrod, 1988; Schwarz et al., 1995). Thus, in view of the CsA-induced NO diminishment previously reported in our model (Santiago et al., 2003), the CsA effects on left ventricle and aorta catecholamines contents might hypothetically be explained by a suppression of the NO-mediated inhibition of catecholamines release by those tissues. The effect was prevented when the NO donor was administered as preventive therapy, but was not corrected or attenuated when the CsA-evoked changes are already established (CsA + Is-5-Mn).

The hypothesis of CsA treatment prolongation as the merely cause for the aggravation/deterioration in the CsA+Is-5-Mn group (at week 12), in comparison with the 7 weeks of single CsA administration, cannot be fully denied at this moment. However, our preliminary studies, concerning the definition and characterization of this animal model of CsA-induced hypertension, have demonstrated that the blood pressure values and the vascular lesion and platelet morphology profiles were already perfectly established after 7 weeks of CsA treatment, and that no relevant aggravation is observed by prolonging the treatment until the week 12. Thus, the cardiovascular worsening effects here reported should be attributed to additional deleterious actions promoted by the Is-5-Mn per se when the CsA changes are already established and cannot be reverted or attenuated. In any case, our deep conviction about this issue should be further confirmed by means of other studies, namely by testing the parameters now evaluated in a CsA group of 12 weeks.

The precise explanations for the distinct behaviors of Is-5-Mn when used as preventive or as regressive therapy cannot be addresses taken in consideration only the data now obtained, deserving further research. However, based on already known information, we would like to raise another key possibility. As mentioned above, according to previous results from us and from other authors, CsA promotes a decrease NO availability. Additionally, other studies have been suggesting that CsA toxicity is at least in part associated with an oxidative stress state (Assis et al., 1997; Pérez de Lema et al., 1998; Kanji et al., 1999) and with changes on reactive oxygen and nitrogen species formation, which is so far a controversial and under discussion issue (Diederich et al., 1994; Buetler et al., 2000). The hypothetic CsA-induced formation, in our animal model, of NO-derived oxygen and/or nitrogen reactive species, such as the superoxide and peroxynitrite, would hypothetically explain some of the above CsA and Is-5-Mn effects. Actually, peroxynitrite formation is associated with several deleterious effects, namely in the vasculature (Muijsers et al., 1997) and, according to some authors, also causes oxidation and nitration of catecholamines, thus decreasing their concentrations (Daveu et al., 1997; Shelkovnikov et al., 2004). If demonstrated in the ventricle and aorta tissues, the increased NOderived peroxynitrite formation would explain the CsA effect on left ventricle and aorta catecholamine contents as well as the CsA-induced toxicity. Furthermore, it would also explain the prevention of CsA-induced hypertension by the Is-5-Mn preventively used: the NO donor, by supplying a NO basis, might prevent the following CsA-induced NO decrease and peroxynitrite formation, thus contributing to prevent the abovementioned catecholamine changes, as well as the vascular toxicity and hypertension. On the contrary, when the CsA effects were already established by prior treatment (CsA + Is-5-Mn group), Is-5-Mn administration was not only unable to revert them but was probably also responsible for the increased peroxynitrite formation, thus contributing to the even more 
deleterious effects than those of the single CsA treatment. This interesting hypothesis here raised deserve, in any case, further research and elucidation, namely by testing if lower nitrate doses also produced the same dual effects when tested as preventive and regressive/curative therapy for CsAinduced hypertension.

\section{Conclusion}

When used as regressive (curative) therapy, Is-5-Mn was unable to revert or attenuate the CsAinduced plasma, platelets, left ventricle and aorta catecholamine changes and, additionally, the blood pressure values even worsened. On the contrary, preventive Is-5-Mn treatment prevented the left ventricle and aorta catecholamine changes, but increased plasma NE and aorta E accumulation. Even though with those effects, CsA-induced arterial hypertension development was totally prevented. These findings suggest that the SNS, even of relevance, cannot per se fully explain the CsA-induced arterial hypertension development, indicating a probable key influence of the NO-cGMP disturbances. Furthermore, the study also emphasizes that Is-5-Mn might produce beneficial effects only if preventively used. However, considering the changes on catecholamine contents here reported, a judicious evaluation of the nitrate therapy impact at a given moment and situation is recommended in order to avoid further deleterious side effects.

\section{Acknowledgments}

This study had the kind collaboration of Novartis Farma (Lisbon, Portugal) that has yielded the cyclosporin A (Sandimmune Neoral ${ }^{\circledR}$ ) and of Ferraz-Lynce (Lisbon, Portugal) which friendly supplied the isosorbide 5-mononitrate (Monopront $\left.{ }^{\circledR}\right)$.

\section{References}

Assis, S.M.A., Monteiro, J.L., Seguro, A.C., 1997. L-Arginine and allopurinol protect against cyclosporine nephrotoxicity. Hypertension 63, 1070-1073.

Bouhaddi, M., Delbosc, B., Fortrat, J.-O., Henriet, M.-T., Cappelle, S., Ducloux, D., Chalopin, J.-M., Regnard, J., 2004. Sixmonth cardiovascular changes in cyclosporine-treated recipients of corneal grafts: serial baroreflex responses. Transplant International 17, 325-333.

Buetler, T.M., Cottet-Maire, F., Krauskopf, A., Ruegg, T., 2000. Does cyclosporin A generate free radicals? Trends in Pharmacological Sciences 21, 288-290.

Cartier, R., Dagenais, F., Hollmann, C., Cambron, H., Buluran, J., 1994. Chronic exposure to cyclosporine affects endothelial and smooth muscle reactivity in the rat aorta. Annals of Thoracic Surgery 58, 789-794.

Carvalho, M.J., van der Meiracker, A.H., Boomsma, F., Freitas, J., Man in ’t Velt, A.J., Costa, O., Freitas, A.F., 1999. Role of sympathetic nervous system in cyclosporine-induced rise in blood pressure. Hypertension 34, $102-106$.

Cattaneo, D., Perico, N., Gaspari, F., Remuzzi, G., 2004. Nephrotoxic aspects of cyclosporine. Transplantation Proceedings 36, 234S-239S.

Chanberlain, K.G., Pestell, R.G., Best, J.D., 1990. Platelet catecholamine contents are cumulative indexes of sympathoadrenal activity. American Journal of Physiology 259, 141-147.

Cohen, R.A., Weisbrod, R.M., 1988. Endothelium inhibits norepinephrine release from adrenergic nerves of rabbit carotid artery. American Journal of Physiology 254, H871-H878. 
Cortesini, R., 2004. Cyclosporine-lessons from the first 20 years. Transplantation Proceedings 36, 158S-162S.

Das, S., Kumar, K.N., 1995. Nitric oxide: its identity and role in blood pressure control. Life Sciences 57, 1547-1556.

Daveu, C., Servy, C., Dendane, M., Marin, P., Ducrocq, C., 1997. Oxidation and nitration of catecholamines by nitrogen oxides derived from nitric oxide. Nitric Oxide 1, 234-243.

Diederich, D., Skopec, J., Diederich, A., Dai, F.-X., 1994. Cyclosporine produces endothelial dysfunction by increased production of superoxide. Hypertension 23, 957-961.

Duruibe, V.A., Okonmah, A., Panton, L., Blyden, G.T., 1990. Effect of cyclosporin A on rat kidney catecholamines. Life Sciences 47, 255-261.

Elam, M., Casale, R., La Rovere, M.-T., Mortara, A., Tavazzi, L., 1993. Is sympathetic neural hyperactivity in chronic heart failure affected by heart transplantation? European Heart Journal 14, 521-525.

El-Mas, M.M., Mohy El-Din, M.M., El-Gowilly, S.M., Sharabi, F.M., 2004. Relative roles of endothelial relaxing factors in cyclosporine-induced impairment of cholinergic and beta-adrenergic renal vasodilations. European Journal of Pharmacology 487, $149-158$.

Floras, J.S., Legault, L., Morali, G.A., Hara, K., Blendis, L.M., 1991. Increased sympathetic outflow in cirrhosis and ascites: direct evidence from intraneural recordings. Annals of Internal Medicine 114, 373-380.

Kanji, V.K., Wang, C., Salahudeen, A.K., 1999. Vitamin E suppresses cyclosporine A-induced increase in urinary excretion of arachidonic acid metabolites including F2-isoprostanes in the rat model. Transplantation Proceedings 31, 1724-1728.

Kaye, D., Thompson, J., Jennings, G., Esler, M., 1993. Cyclosporine therapy after cardiac transplantation causes hypertension and renal vasoconstriction without sympathetic activation. Circulation 88, 1101-1109.

Lassila, M., Santisteban, J., Finckenberg, P., Salmenperä, P., Riutta, A., Moilanen, E., Virtanen, I., Vapaatalo, H., Nurminen, M.L., 2001. Vascular changes in cyclosporine A-induced hypertension and nephrotoxicity in spontaneously hypertensive rats on high-sodium diet. Journal of Physiology and Pharmacology 52, 21-38.

Lucini, D.L., Milani, R.V., Ventura, H.O., Mehra, M.R., Messerli, F.H., Pagani, M., 2000. Study of arterial and autonomic effects of cyclosporine in humans. Hypertension 35, 1258-1263.

Lyson, T., McMullan, D.M., Ermel, L.D., Morgan, B.J., Victor, R.G., 1994. Mechanisms of cyclosporine-induced sympathetic activation and acute hypertension in rats. Hypertension 23, 667-675.

Mange, K.C., Cizman, B., Joffe, M., Feldman, H.I., 2000. Arterial hypertension and renal allograft survival. Journal of the American Medical Association 283, 633-638.

Marumo, T., Nakaki, T., Hishikawa, K., Suzuki, H., Kato, R., Saruta, T., 1995. Cyclosporin A inhibits nitric oxide synthase induction in vascular smooth muscle cells. Hypertension 25, 764-768.

Megson, I.L., 2000. Nitric oxide donor drugs. Drugs of the Future 25, 701-715.

Muijsers, R.B., Folkerts, G., Henricks, P.A., Sadeghi-Hashjin, G., Nijkamp, F.P., 1997. Peroxynitrite: a two-faced metabolite of nitric oxide. Life Sciences 60, 1833-1845.

O’Neil, G.S., Chester, A.H., Kushwaha, S., Rose, M., Tadjkarimi, S., Yacoub, M.H., 1991. Cyclosporin treatment does not impair the release of nitric oxide in human coronary arteries. British Heart Journal 66, 212-216.

Oriji, G.K., Keiser, H.R., 1998. Role of nitric oxide in cyclosporin A-induced hypertension. Hypertension 32, 849-855.

Pérez de Lema, G., Arribas, I., Prieto, A., Parra, T., de Arriba, G., Rodríguez-Puyol, D., Rodríguez-Puyol, M., 1998. Cyclosporin A-induced hydrogen peroxide synthesis by cultured human mesangial cells is blocked by exogenous antioxidants. Life Sciences 62, 1745-1753.

Reis, F., Tavares, P., Teixeira, F., 2000. The distribution of catecholamines between plasma and platelets in cyclosporin Ainduced hypertensive rats. Pharmacological Research 41, 129-135.

Reis, F., Santiago, M., Almeida, L., Alcobia, T., Santos-Dias, J.D., Mesquita, J.F., Pontes, F., Teixeira, F., 2002. Isosorbide-5mononitrate and L-arginine effect on the cyclosporin-induced arterial hypertension and vascular nitric oxide impairment. In: Tooke, J., Shore, A., Whatmore, J. (Eds.), The Microcirculation and Vascular Biology. Monduzzi Editore S.p.A, Bologna, Italy, pp. 257-261.

Reis, F., Almeida, L., Alcobia, T., Santos-Dias, J.D., Lourenço, M., Palmeiro, A., Ferrer-Antunes, C.A., Mesquita, J.F., Pontes, F., Teixeira, F., 2003. Isosorbide-5-mononitrate treatment prevents cyclosporin A-induced platelet hyperactivation and the underlying nitric oxide-cyclic guanosine- $3^{\prime}, 5^{\prime}$-monophosphate disturbances. Thrombosis Research 110, $107-115$.

Sander, M., Lyson, T., Thomas, G.D., Victor, R.G., 1996. Sympathetic neural mechanisms of cyclosporine-induced hypertension. American Journal of Hypertension 9, 121S-138S. 
Santiago, M., Reis, F., Almeida, L., Alcobia, T., Dionísio, J., Teixeira, F., 2003. Impairment of vascular and platelet nitric oxide and $3^{\prime}, 5^{\prime}$ cyclic guanosine monophosphate content in cyclosporin A-induced hypertensive rats. Fundamental and Clinical Pharmacology $17,43-50$.

Scherrer, U., Vissing, S.F., Morgan, B.J., Rollins, J.Á., Tindall, R.S.A., Ring, S., Hanson, P., Mohanty, P.K., Victor, R.G., 1990. Cyclosporine-induced sympathetic activation and hypertension after heart transplantation. New England Journal of Medicine 323, 693-699.

Schwarz, P., Diem, R., Dun, N.J., Forstermann, U., 1995. Endogenous and exogenous nitric oxide inhibits norepinephrine release from rat heart sympathetic nerves. Circulation Research 77, 841-848.

Seals, D.R., Suwarno, N.O., Joyner, M.J., Iber, C., Copeland, J.G., Dempsey, J.A., 1993. Respiratory modulation of muscle sympathetic nerve activity in intact and lung denervated humans. Circulation Research 72, 440-454.

Shelkovnikov, S., Merlic, C.A., Gonick, H.C., 2004. Influence of nitric oxide donors and peroxynitrite on the contractile effect and concentration of norepinephrine. Life Sciences 74, 2919-2928.

Stahl, S.M., 1985. Platelets as pharmacologic models for the receptors and biochemistry of monoaminergic neurons. In: Longenecker, G.L. (Ed.), The Platelets: Physiology and Pharmacology. Academic Press, London, pp. $307-340$.

Stein, C.M., He, H., Pincus, T., Wood, A.J., 1995. Cyclosporine impairs vasodilation without increased sympathetic activity in humans. Hypertension 26, 705-710.

Stephan, D., Billing, A., Krieger, J.P., Erima, M., Fabre, M., Hafner, M., Imbs, J.L., Barthelmebs, M., 1995. Endotheliumdependent relaxation in the isolated rat kidney: impairment by cyclosporine A. Journal of Cardiovascular Pharmacology 26, 859-868.

Stroes, E.S., Luscher, T.F., Groot, F.G., Koomans, H.A., Rabelink, T.J., 1997. Cyclosporin A increases nitric oxide activity in vivo. Hypertension 29, 570-575.

Taler, S.J., Textor, S.C., Canzanello, V.J., Schwartz, L., 1999. Cyclosporin-induced hypertension: incidence, pathogenesis and management. Drug Safety 20, 437-449.

Tavares, P., Reis, F., Fontes-Ribeiro, C.A., Teixeira, F., 2002. Cardiovascular effects of cyclosporin treatment in an experimental model. Revista Portuguesa de Cardiologia 21, 141-155.

Tavares, P., Fontes-Ribeiro, C.A., Teixeira, F., 2003. Cyclosporin effect on noradrenaline release from sympathetic nervous endings of rat aorta. Pharmacological Research 47, 27-33.

Textor, S.C., Taler, S.J., Canzanello, V.J., Schwartz, L., Augustine, J.E., 2000. Posttransplantation hypertension related to calcineurin inhibitors. Liver Transplantation 6, 521-530.

van de Borne, P., Neubauer, J., Rahnama, M., Jansens, J.-L., Montano, N., Porta, A., Somers, V.K., Degaute, J.P., 2001. Differential characteristics of neural circulatory control- early versus late after cardiac transplantation. Circulation 104, $1809-1813$.

Xue, H., Buroski, R.D., McCarron, D.A., Bennett, W.M., 1987. Induction of contraction in isolated rat aorta by cyclosporine. Transplantation 43, 715-718.

Zhang, W., Victor, R.G., 2000. Calcineurin inhibitors cause renal afferent activation in rats: a novel mechanism of cyclosporineinduced hypertension. American Journal of Hypertension 13, 999-1004.

Zoja, C., Furci, L., Ghilardi, F., Zilio, P., Benigni, A., Remuzzi, G., 1986. Cyclosporin-induced endothelial cell injury. Laboratory Investigation 55, 455-462. 